\title{
The Significance of Aldehyde Dehydrogenase 1A1 Expression in Colorectal Carcinoma
}

\author{
Eman M. Zedan, Hanaa M. Ali, Nashwa M. Emara, Hala A. Agina
}

Department of Pathology, Faculty of Medicine, Benha University, Egypt.

Correspondence to: Hanaa M. Ali, Department of Pathology, Faculty of Medicine, Benha University, Egypt.

Email:

hanaa.abostate773@gmail.com

Received: 10 October 2020

Accepted: 7 August 2021

\begin{abstract}
:
Background: Colorectal carcinoma (CRC) is the third most common cancer in the world constituting about $10 \%$ of all cancers. ALDH1A1 has been used as a stem cell marker, and plays important functional roles in stem cells. Expression of ALDH1A1 by cancer stem cells (CSCs) has been demonstrated in multiple types of cancers. Aim: This work aimed to evaluate ALDH1A1 expression in colorectal adenocarcinoma and determine the relation between ALDH1A1 expression and different clinico-pathological variables.
\end{abstract} Material and method: This is a selected retrospective study which included 50 different cases of colorectal adenocarcinoma. ALDH1A1 immunostaining was performed for all cases. Results: There was a highly significant statistical difference between ALDH1A1 expression in studied cases according to tumor site, lymph node metastasis and TNM stage ( $\mathrm{P}$ value $<0.01$ ). Also, there was a significant statistical difference according to lymphovascular and perineural invasion ( $\mathrm{P}$ value $<0.05$ ). Other clinico-pathological variables such as age, sex, tumor size, histopathological subtype, tumor grade, depth of tumor invasion and distant metastasis showed no significant statistical difference ( $\mathrm{P}$ value >0.05). Conclusion: High ALDH1A1 expression was associated with right sided tumors, lymphovascular invasion, perineural invasion and lymph node metastasis in colorectal carcinoma. ALDH1A1 may play an important role in tumor invasion and lymph node metastasis and may work as a useful marker for prognosis of CRC.

Keywords: Colorectal adenocarcinoma, ALDH1A1, stem cell marker.

Abbreviations: Colorectal carcinoma (CRC), Aldehyde dehydrogenases 1A1 (ALDH1A1), cancer stem cells (CSCs). 


\section{Introduction:}

Colorectal carcinoma (CRC) is the third most common cancer in the world, constituting about $10 \%$ of all cancers. It is the second most common cause of cancerrelated deaths throughout the world with 1.8 million new cases and almost 881,000 deaths in 2018 (1).

In Egypt, according to National cancer institute registry, Cairo University, colorectal carcinoma constitutes $35 \%$ of total gastrointestinal tract malignancies and $6.49 \%$ of all malignancies (2).

Life style factors associated with risk of CRC include smoking, alcohol intake, high red meat and processed meat consumption, high fat and protein diet intake, physical inactivity, and overweight. According to the National Institute for Clinical Excellence, about three quarters of CRC cases are associated with the population lifestyle (3).

Clinicopathological parameters play an important role in management of CRC. However, they are usually not reliable predictors of prognosis (4). Therefore, studying novel biomarkers, which have the potential value of serving as prognostic markers and new therapeutic targets, are still a clinical problem to be solved (5).
Cancer stem cells (CSCs) are cancer cells that are responsible for initiation, progression, metastasis, and recurrence of cancer. CSC theory in colorectal carcinoma has been investigated and several stem cell markers have been studied (6).

Aldehyde dehydrogenase 1A1 (ALDH1A1), a main member of the Aldehyde dehydrogenase (ALDH) superfamily, catabolizes the oxidation of intracellular aldehydes, and it has a critical role in stem cell differentiation and protection (7).

Colorectal cancers are molecularly and histologically heterogeneous, reflecting different pathways of carcinogenesis (8).

The correlation between increased enzymatic activities of Aldehyde dehydrogenase with cancer stem cells properties has been shown in a wide spectrum of malignancies. Expression of ALDH1A1 by cancer stem cells has been demonstrated in multiple types of cancers such as stomach, breast and lung cancer (9).

However, the significance of ALDH1A1 protein expression in colorectal carcinoma remains unclear and the study aims to 
evaluate the significance of its expression in Egyptian colorectal carcinoma cases.

\section{Material and methods:}

\section{Study Groups:}

This selected retrospective study included 50 different cases of colorectal adenocarcinoma designated as; 38 cases of conventional adenocarcinoma, 6 cases of mucinous adenocarcinoma and 6 cases of signet ring cell carcinoma (all cases were right or left colectomy specimens). Six control cases were taken from viable margins in patients with intestinal infarction. Sections of normal liver tissue (adjacent liver tissue to cholecystectomy specimen) were taken as a positive control for ALDH1A1 immunohistochemical expression.

The material included archival formalin fixed paraffin embedded blocks processed during the years 2015-2020 as well as stained Hematoxylin and Eosin (H\&E) slides for review. The blocks were retrieved from Pathology Department and Early Cancer Detection Unit archives; faculty of medicine, Benha University, Egypt. Clinicopathological data were collected from the files of patients. Being a retrospective study, a written informed consent was not needed. The study was approved by the Research Ethics committee of Faculty of Medicine, Benha University, Egypt.

\section{Histopathological studies:}

Re-evaluation of sections from all selected cases, unaware of their diagnosis, was performed. The cases were re-evaluated for their subtype and graded into well differentiated, moderately differentiated, and poorly differentiated tumors (10). Lymph node status was evaluated and TNM staging system was applied to the cases according to AJCC, $8^{\text {th }}$ edition (11, 12).

\section{ALDH1A1 immunohistochemical study:}

Slides were immunostained according to manufacturer's instructions with ALDH1A1 rabbit polyclonal antibody (Chongqing biopsies co., Cat No YPA1390, China, conc) at a dilution of 1:50, at room temperature overnight. Immunodetection was carried out using a standard labeled streptavidin-biotin system (Genemed, CA 94080, USA, South San Francisco). Antigen retrieval was done by using 10 mmol/L citrate monohydrate buffer $(\mathrm{pH}$ 6.0) and heating for 15 minutes in the microwave. Freshly prepared chromogen diaminobenzine (DAB, Envision ${ }^{\mathrm{TM}}$ Flex /HRP-Dako, REF K 8000) was used. Negative (cold Phosphate- buffered Saline) 
and positive control (normal liver tissue) were enclosed in each run $(\mathbf{1 3}, \mathbf{1 4})$.

\section{Interpretation of ALDH1A1 expression:}

Positivity was considered as brownish homogenous cytoplasmic staining of tumor cells (15). The immunohistochemical scores were obtained by light microscopy (Olympus, Tokyo, Japan) as the staining intensity (scored from 0-3) multiplied by the percentage of positive cells within 5 high power fields (in hot areas) (scored from 0-4). The intensity of ALDH1A1 protein expression was scored as: 0 (no staining); 1 (weak staining); 2 (moderate staining); or 3 (strong staining). The percentage of positive cells was scored as: $0(<5 \%) ; 1(5-25 \%) ; 2$ (26-50\%); 3 (51$75 \%)$; or $4(>75 \%)$. The cut-off value for high versus low expression of the ALDH1A1 protein was determined using receiver-operating characteristic (ROC) curve analysis and SPSS statistical software, defining a final immunostaining score of $>3.5$ as high ALDH1A1 protein expression (16) (figure 1, table 5).

\section{Statistical analysis:}

Categorical data were presented as number and percentages while quantitative data were expressed as mean \pm standard deviation (SD). Chi square test $\left(\chi^{2}\right)$, or Fisher's exact test were used to analyze categorical variables. Quantitative data were tested for normality using ShapiroWilks test, assuming normality at $\mathrm{P}>0.05$, using Student " $\mathrm{t}$ " test if normally distributed, or Man-Whitney $U$ test and Kruskal-Wallis test if not normally distributed for analyzing the difference. Receiver-operating characteristic (ROC) curve was used to predict sensitivity, specificity and accuracy of immunohistochemical score to detect lymph node invasion. Differences were considered significant at a calculated $\mathrm{P}$ value of $<0.05$. Statistical analysis was performed using SPSS version 25 (SPSS Inc, Chicago, IL, USA).

\section{Results:}

\section{Demographic and clinical parameters:}

This study was carried upon 50 cases of colorectal adenocarcinoma, 28 cases $(56 \%)$ were males and 22 cases (44\%) were females. The age of studied cases ranged between 30- 80 years with the mean age $55 \pm 13.7$ years. 23 cases $(46 \%)$ aged $<55$ years and 27 cases $(54 \%)$ aged $\geq 55$ years.

\section{Histopathological results:}

Thirty-six cases $(72 \%)$ were located in the right colon and 14 cases (28\%) were located in the left colon. Tumor size ranged from $3 \mathrm{~cm}$ to $12 \mathrm{~cm}$ in the largest dimension, 
with mean size $6.5 \mathrm{~cm}$ (Mean $\pm \mathrm{SD}=$ $6.5 \pm 2.2)$. Twenty six cases $(52 \%)$ were < $6.5 \mathrm{~cm}$, while 24 cases $(48 \%)$ were $\geq 6.5$ $\mathrm{cm}$. As regard depth of tumor invasion, 2 cases $(4 \%)$ were T2, 21 cases $(42 \%)$ were T3 and 27 cases (54\%) were T4. Lymphovascular invasion was detected in 39 cases $(78 \%)$, while no lymphovascular invasion was detected in 11 cases (22\%). Perineural invasion was detected in 17 cases $(34 \%)$, while no perineural invasion was detected in 33 cases $(66 \%)$. Regional lymph node metastasis was detected in 33 cases $(66 \%)$, while 17 cases (34\%) were free of regional lymph node metastasis (N0).

Table 1: Comparison between histopathological subtypes according to the grade of studied cases.

\begin{tabular}{|c|c|c|c|c|c|}
\hline Histopathological subtype & $\begin{array}{c}\text { Grade I } \\
(\mathbf{N}=3)\end{array}$ & $\begin{array}{c}\text { Grade II } \\
(\mathbf{N}=33)\end{array}$ & $\begin{array}{l}\text { Grade III } \\
(\mathrm{N}=14)\end{array}$ & $\begin{array}{c}\text { Test of } \\
\text { significance }\end{array}$ & P-value \\
\hline $\begin{array}{l}\text { Conventional adenocarcinoma } \\
(\mathrm{N}=38)\end{array}$ & $3(7.9 \%)$ & $31(81.6 \%)$ & $4(10.5 \%)$ & & \\
\hline $\begin{array}{l}\text { Mucinous adenocarcinoma } \\
(\mathrm{N}=6)\end{array}$ & 0 & $2(33.3 \%)$ & $4(66.7 \%)$ & & \\
\hline $\begin{array}{l}\text { Signet ring cell carcinoma } \\
(\mathrm{N}=6)\end{array}$ & 0 & 0 & $6(100 \%)$ & $\mathrm{FET}=22.7$ & $<0.001 * *$ \\
\hline
\end{tabular}

$\mathrm{N}$, number; FET, fisher exact test, ** highly significant.

Table 2: Comparison between histopathological subtypes according to the stage of studied cases.

\begin{tabular}{|c|c|c|c|c|c|}
\hline Histopathological subtype & $\begin{array}{l}\text { Stage II } \\
(\mathrm{N}=15)\end{array}$ & $\begin{array}{l}\text { Stage III } \\
(\mathrm{N}=28)\end{array}$ & $\begin{array}{l}\text { Stage IV } \\
(\mathrm{N}=7)\end{array}$ & $\begin{array}{c}\text { Test of } \\
\text { significance }\end{array}$ & P-value \\
\hline $\begin{array}{l}\text { Conventional } \\
\text { adenocarcinoma } \quad(\mathrm{N}=38)\end{array}$ & $\begin{array}{c}15 \\
(39.4 \%)\end{array}$ & $21(55.3 \%)$ & $2(5.3 \%)$ & & \\
\hline $\begin{array}{l}\text { Mucinous adenocarcinoma } \\
(\mathrm{N}=6)\end{array}$ & 0 & $4(66.7)$ & $2(33.3)$ & FET $=12.5$ & $0.005 * *$ \\
\hline $\begin{array}{l}\text { Signet ring cell carcinoma } \\
(\mathrm{N}=6)\end{array}$ & $\mathbf{0}$ & $3(50 \%)$ & $3(50 \%)$ & & \\
\hline
\end{tabular}

$\mathrm{N}$, number; FET, fisher exact test, $* *$ highly significant. 
Table 3: Comparison between the grades regarding the stage of studied cases (TNM).

\begin{tabular}{cccccc}
\hline Tumor grade & $\begin{array}{c}\text { Stage II } \\
(\mathrm{N}=15)\end{array}$ & $\begin{array}{c}\text { Stage III } \\
(\mathrm{N}=28)\end{array}$ & $\begin{array}{c}\text { Stage IV } \\
(\mathrm{N}=7)\end{array}$ & $\begin{array}{c}\text { Test of } \\
\text { significance }\end{array}$ & P-value \\
\hline $\begin{array}{c}\text { Grade I } \\
(\mathrm{N}=3)\end{array}$ & $2(66.7 \%)$ & 0 & $1(33.3 \%)$ & & \\
$\begin{array}{c}\text { Grade II } \\
(\mathrm{N}=33)\end{array}$ & $11(33.3 \%)$ & $19(57.6 \%)$ & $3(9.1 \%)$ & FET $=6.98$ & 0.095 \\
$\begin{array}{c}\text { Grade III } \\
(\mathrm{N}=14)\end{array}$ & $2(14.3 \%)$ & $9(64.3 \%)$ & $3(21.4 \%)$ & & \\
\hline
\end{tabular}

$\mathrm{N}$, number; FET, fisher exact test

\section{Immunohistochemical results:}

- In apparently normal colorectal mucosa (control cases), ALDH1A1 displayed a heterogeneous pattern, ranging from no staining at all to uniform staining throughout the whole crypts (fig. 2-a). These findings were in agreement with other study in CRC (17).

- ALDH1A1 expression in studied CRC cases:

Out of 50 cases of $\mathrm{CRC}, 24$ cases (48\%) showed low ALDH1A1 expression and 26 cases $(52 \%)$ showed high expression (fig. 2b, c, d, e and f).
Statistical analysis was performed on the relation between ALDH1A1 expression in studied CRC cases and clinico-pathological variables. It revealed a highly significant statistical difference between ALDH1A1 expression in studied cases according to tumor site, lymph node metastasis and TNM stage $(\mathrm{P}$ value $=0.007,0.001$ and $<0.001$ respectively). It also revealed a significant statistical difference according to lymphovascular and perineural invasion $(\mathrm{P}$ value $=0.011$ and 0.013 respectively). Other clinico-pathological variables showed no significant statistical difference (table 4). 
Table (4): Comparison between ALDH1A1 expression in studied cases according to clinico-pathological features:

\begin{tabular}{|c|c|c|c|c|c|}
\hline \multirow{2}{*}{\multicolumn{2}{|c|}{ Clinico-pathological features }} & \multirow{3}{*}{$\begin{array}{c}\text { Total } \\
23\end{array}$} & \multicolumn{2}{|c|}{ ALDH1A1 expression } & \multirow{3}{*}{ P-value } \\
\hline & & & \multirow{3}{*}{$\begin{array}{c}\begin{array}{c}\text { Low } \\
\text { expression }\end{array} \\
11(47.8 \%) \\
13(48.1 \%)\end{array}$} & \multirow{2}{*}{$\begin{array}{c}\begin{array}{c}\text { High } \\
\text { expression }\end{array} \\
12(52.2 \%)\end{array}$} & \\
\hline \multirow{2}{*}{$\begin{array}{l}\text { Age }(\text { years }) \\
(\text { mean }=55 \pm 13.7)\end{array}$} & $<55$ & & & & \\
\hline & $\geq 55$ & 27 & & $14(51.9 \%)$ & 0.982 \\
\hline \multirow{2}{*}{ Gender } & Male & 28 & $13(46.4 \%)$ & $15(53.6 \%)$ & \multirow{2}{*}{0.802} \\
\hline & Female & 22 & $11(50 \%)$ & $11(50 \%)$ & \\
\hline \multirow{2}{*}{ Tumor site } & Right colon & 36 & $13(36.1 \%)$ & $23(63.9 \%)$ & \multirow{2}{*}{$0.007 * *$} \\
\hline & Left colon & 14 & $11(78.6 \%)$ & $3(21.4 \%)$ & \\
\hline \multirow{3}{*}{$\begin{array}{l}\text { Tumor size (Mean } \\
=6.5 \pm 2.2 \text { ) }\end{array}$} & $<6.5 \mathrm{~cm}$ & 26 & $15(57.7 \%)$ & $11(42.3 \%)$ & \multirow{2}{*}{0.153} \\
\hline & $\geq 6.5 \mathrm{~cm}$ & 24 & $9(37.5 \%)$ & $15(62.5 \%)$ & \\
\hline & $\begin{array}{l}\text { Conventional } \\
\text { adenocarcinoma }\end{array}$ & 38 & $20(52.6 \%)$ & $18(47.4 \%)$ & \multirow{3}{*}{0.573} \\
\hline \multirow[t]{3}{*}{ Tumor subtype } & $\begin{array}{l}\text { Mucinous } \\
\text { adenocarcinoma }\end{array}$ & 6 & $2(33.3 \%)$ & $4(66.7 \%)$ & \\
\hline & $\begin{array}{l}\text { Signet ring cell } \\
\text { carcinoma }\end{array}$ & 6 & $2(33.3 \%)$ & $4(66.7 \%)$ & \\
\hline & Grade I & 3 & $3(100 \%)$ & 0 & \multirow{3}{*}{0.065} \\
\hline \multirow[t]{2}{*}{ Tumor grade } & Grade II & 33 & $17(51.5 \%)$ & $16(48.5 \%)$ & \\
\hline & Grade III & 14 & $4(28.6 \%)$ & $10(71.4 \%)$ & \\
\hline \multirow{3}{*}{$\begin{array}{l}\text { Depth of tumor } \\
\text { invasion }(T)\end{array}$} & $\mathbf{T} 2$ & 2 & $1(50 \%)$ & $1(50 \%)$ & \multirow{3}{*}{0.194} \\
\hline & T3 & 21 & $13(61.9 \%)$ & $8(38.1 \%)$ & \\
\hline & $\mathbf{T 4}$ & 27 & $10(37 \%)$ & $17(63 \%)$ & \\
\hline \multirow{2}{*}{$\begin{array}{l}\text { Lymphovascular } \\
\text { invasion }\end{array}$} & Present & 39 & $15(38.5 \%)$ & $24(61.5 \%)$ & \multirow{2}{*}{$0.011^{*}$} \\
\hline & Absent & 11 & $9(81.8 \%)$ & $2(18.2 \%)$ & \\
\hline \multirow{2}{*}{$\begin{array}{l}\text { Perineural } \\
\text { invasion }\end{array}$} & Present & 17 & $4(23.5 \%)$ & $13(76.5 \%)$ & \multirow{2}{*}{$0.013^{*}$} \\
\hline & Absent & 33 & $20(60.6 \%)$ & $13(39.4 \%)$ & \\
\hline \multirow{3}{*}{$\begin{array}{l}\text { Lymph node } \\
\text { metastasis (N) }\end{array}$} & No & 17 & $14(82.4 \%)$ & $3(17.6 \%)$ & \multirow{3}{*}{$0.001 * *$} \\
\hline & N1 & 14 & $6(42.9 \%)$ & $8(57.1 \%)$ & \\
\hline & $\mathbf{N} 2$ & 19 & $4(21.1 \%)$ & $15(78.9 \%)$ & \\
\hline \multirow{2}{*}{$\begin{array}{l}\text { Distant metastasis } \\
\text { (M) }\end{array}$} & M0 & 43 & $19(44.2 \%)$ & $24(55.8 \%)$ & \multirow{2}{*}{0.239} \\
\hline & M1 & 7 & $5(71.4 \%)$ & $2(28.6 \%)$ & \\
\hline \multirow{3}{*}{$\begin{array}{l}\text { Tumor stage } \\
\text { (TNM) }\end{array}$} & Stage II & 15 & $13(86.7 \%)$ & $2(13.3 \%)$ & \multirow{3}{*}{$<0.001 * *$} \\
\hline & Stage III & 28 & $6(21.4 \%)$ & $22(78.6 \%)$ & \\
\hline & Stage IV & 7 & $5(71.4 \%)$ & $2(28.6 \%)$ & \\
\hline
\end{tabular}

ALDH1A1, Aldehyde dehydrogenase 1A1; * significant; ** highly significant. 


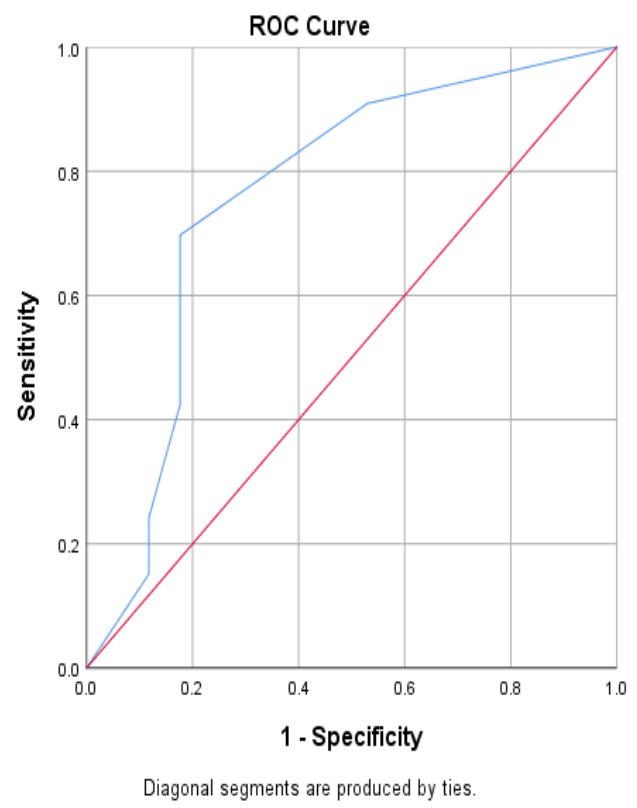

Figure (1): Receiver-operating characteristic curve analysis to determine cut-off score for ALDH1A1 expression.

Table (5): Validity of immunohistochemical score in prediction of lymph node metastasis.

\begin{tabular}{lllllll}
\hline $\begin{array}{l}\text { Immunohistochemical } \\
\text { score }\end{array}$ & $\begin{array}{l}\text { Positive LN metastasis } \\
(33)\end{array}$ & $\begin{array}{l}\text { Negative LN metastasis } \\
(17)\end{array}$ & $\begin{array}{l}\text { Statistical } \\
\text { test }\left(\mathbf{x}^{2}\right)\end{array}$ & P value \\
& No & $\%$ & No & $\%$ & & \\
\hline Positive & 23 & 69.7 & 3 & 17.6 & 12.18 & $<0.001 * *$ \\
Negative & 10 & 30.3 & 14 & 82.4 & & \\
AUC(95\% CI) & 0.761 & $(0.604-0.918)$ & & & & \\
Cut-off point & 3.5 & & & & & \\
Sensitivity & 69.7 & & & & & \\
Specificity & 82.4 & & & & & \\
PPV & 88.5 & & & & & \\
NPV & 58.3 & & & & & \\
Accuracy & 74.0 & & & & & \\
\hline
\end{tabular}

AUC, area under the curve; PPV, positive predictive value; NPV, negative predictive value; LN, lymph node.

Receiver-operating characteristic (ROC) curve was used to predict sensitivity, specificity and accuracy of immunohistochemical score to detect lymph node metastasis. Sensitivity was $69.7 \%$, specificity was $82.4 \%$ and accuracy was $74 \%$. 


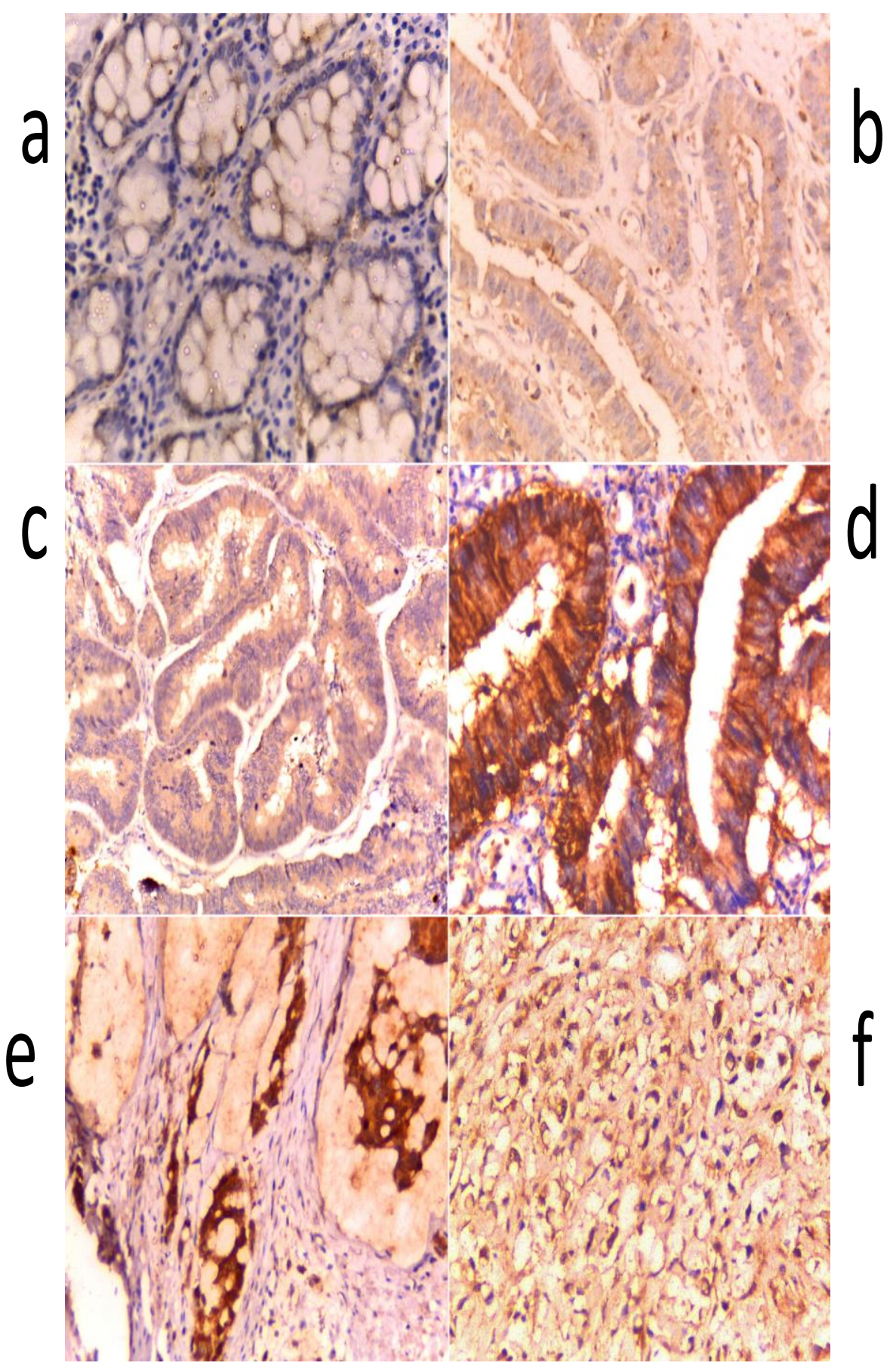

Figure (2): a- Normal colonic mucosa with scattered epithelial cells showing weak cytoplasmic staining of ALDH1A1 (score 2) (ABC X400). b- Adenocarcinoma, grade I showing weak cytoplasmic staining of ALDH1A1 (score 3) (ABC X400). c- Adenocarcinoma, grade II showing moderate cytoplasmic staining of ALDH1A1 (score 6) (ABC X200). d- Adenocarcinoma, grade II showing strong cytoplasmic staining of ALDH1A1 (score 12) (ABC X400). e- Mucinous adenocarcinoma, showing strong cytoplasmic staining of ALDH1A1 (score 9) (ABC X400). f- Signet ring cell carcinoma, showing moderate cytoplasmic staining of ALDH1A1 (score 8) (ABC X400). 


\section{Discussion:}

Colorectal carcinoma is one of the most common cancers worldwide and represents one of the major causes of cancer related deaths throughout the world (1).

In our study, there was a highly significant statistical difference between histopathological subtypes according to the grade and stage of studied cases.

Regarding grade, $81.6 \%$ of conventional adenocarcinoma cases were grade II while $66.7 \%$ of mucinous adenocarcinoma and all signet ring cell carcinoma cases were grade III as signet ring cell carcinoma is a poorly differentiated tumor by definition (18). Regarding stage, conventional adenocarcinoma cases were mainly stage II and III while mucinous and signet ring carcinoma were mainly stage III and IV. These results were matched with Nitsche et al., (19).

In accordance with many studies, mucinous adenocarcinoma and signet ring cell carcinoma had more advanced stages (20, 21) and higher grade (21, 22). These findings were more demonstrated with signet ring cell carcinoma than with mucinous adenocarcinoma. This may be explained by the more aggressive tumor biology of mucinous adenocarcinoma and particularly signet ring cell carcinoma when compared with conventional adenocarcinoma $(\mathbf{1 9}, \mathbf{2 3})$.

Comparison between the grades regarding the stage of studied cases was also performed with no statistically significant difference. Sixty-six and seven tenths percent of grade I cases were stage II, while $57.6 \%$ of grade II and $64.3 \%$ of grade III cases were stage III. This may suggest high grade tumors are usually associated with lymph node metastases (stage III). In contrast, low-grade tumors have fewer lymph node metastases.

These results were in agreement with a study performed by Derwinger et al., (24) on 1239 cases of CRC, who found that high grade tumors were associated with presence of lymph node metastasis with a larger number of positive lymph nodes. The tumor grade in their study was significantly correlated with the overall TNM stage. The significant correlation may be due to the larger number of cases in their study.

ALDH1A1 has been used as a stem cell marker, and plays important functional roles in stem cells (9).

In the current study, $48 \%$ of studied CRC cases showed low ALDH1A1 expression 
and 52\% showed high expression. These results were close to those of Yang et al., (16) and van der Waals et al., (15).

In this study, there was a highly significant statistical difference between tumor site and ALDH1A1 expression. In right colon cases, $63.9 \%$ showed high expression while $78.6 \%$ of left colon cases showed low expression. These results were matched with van der Waals et al., (15) who found that ALDH1A1 expression in untreated rightsided tumors was significantly higher (3.8fold) when compared to left-sided tumors and Holah et al., (25) who found a statistically significant association between ALDH1 positivity and right sided tumors. They explained that right-sided tumor location is a negative prognostic variable in CRC. Although the exact mechanisms are not clear, differences in clinical, chromosomal and molecular characteristics may play a role in the poor prognosis of these tumors. They are more likely to have high-grade histology and advanced tumor stage at initial presentation compared with left sided tumors. This may predict that increased ALDH1A1 expression in right side might be associated with poor prognosis (26).

In contrast, Yang et al., (16) found insignificant statistical correlation between
ALDH1A1 expression and tumor site. This may be due to different geographic and genetic variability between races because the study was performed on Chinese patients.

Regarding tumor size, $57.7 \%$ of cases with tumor size $<6.5 \mathrm{~cm}$ showed low ALDH1A1 expression while $62.5 \%$ of cases with tumor size $\geq 6.5 \mathrm{~cm}$ showed high expression. However, it didn`t reach a statistical significance value. This agrees with other studies carried out on CRC (16) and gastric carcinoma (27). The increased expression in larger tumor sizes may be explained by the role of ALDH1A1 in increasing tumor growth and cancer stem cell proliferation. ALDH1A1 promotes tumor growth through oxidation of aldehydes and reduction of $\mathrm{NAD}+$ to $\mathrm{NADH}$ by using glutathione (GSH) and dihydrolipoic acid (DHLA) as electron donors (28).

Regarding histopathological subtype, $66.7 \%$ of both mucinous adenocarcinoma and signet ring cell carcinoma cases showed high ALDH1A1 expression while $52.6 \%$ of conventional adenocarcinoma cases showed low expression. There was statistically insignificant difference. These results were in agreement with Holah et al., (25) in their study on 49 cases of CRC, who found insignificant statistical association between 
ALDH1 expression and histopathological subtype with $88.9 \%$ of mucoid carcinoma cases showing positive expression. The increased expression in mucinous and signet ring carcinoma cases may be related to high grade and advanced tumor stage of these tumors.

The current study has shown that $100 \%$ of grade I and $51.5 \%$ of grade II cases showed low expression while $71.4 \%$ of grade III cases showed high expression. However, it didn`t reach a statistical significance value. These results were in line with van der Waals et al., (15) and Lugli et al., (29) in their studies in CRC cases and Althobiti et al., (30) who found that ALDH1A1 expression was associated with high grade in invasive breast carcinoma. The association of ALDH1A1 expression with poor differentiation may reflect the CSC-like nature of ALDH1A1-expressing tumor cells (15). Other studies performed by Penumatsa et al., (31) on cancer ovary, Kahlert et al., (32) on pancreatic carcinoma and Tanaka et al., (33) on hepatocellular carcinoma revealed that well differentiated tumors showed higher expression of ALDH1A1 compared to poorly differentiated tumors. These variabilities of ALDH1A1 expressions among studies may be due to different tissues with different molecular signature or different tissue specificity.

There was statistically insignificant difference between depth of tumor invasion and ALDH1A1 expression. These findings are consistent with those with CRC (16). Other study performed by $\mathbf{L i}$ et al., (27) on gastric carcinoma found a highly significant association between ALDH1A1 expression and depth of tumor invasion. The increased expression of ALDH1A1 with increased depth of invasion may be explained by the role of ALDH1A1 in increasing tumor growth and cancer stem cell proliferation (28). ALDH1A1 also promotes epithelial mesenchymal transition (EMT), an important phenomenon associated with tumor invasion and metastasis (34).

In the current study, there was a statistically significant difference between ALDH1A1 expression regarding lymphovascular invasion. These results were in agreement with Holah et al., (25) study in CRC and Althobiti et al., (30) study in invasive breast carcinoma who found a statistically significant association between ALDH1A1 expression and presence of lymphovascular invasion. ALDH1A1 acts as a promoter, inducing EMT in cancer cells. EMT can stimulate tumor invasion and metastasis through promoting cancer cell progression 
through the basement membrane and invasion into the surrounding microenvironment such as lymphovascular spaces $(\mathbf{3 5}, \mathbf{2 5})$.

The current study has shown that $76.5 \%$ of cases with positive perineural invasion showed high expression of ALDH1A1 with a statistically significant difference. This is in agreement with that reported by Masoud et al., (36) on prostatic carcinoma but not with that by Liu et al., (34) on gastric carcinoma. The increased ALDH1A1 expression in CRC can be explained as most cases with positive perineural invasion $(88.2 \%)$ were also characterized by increased depth of tumor invasion (T4). Also, lymph node metastasis was detected in all cases with positive perineural invasion.

In the current study, there was a highly significant statistical difference between ALDH1A1 expression regarding lymph node metastasis $(\mathrm{P}$-value $=0.001)$. Eightytwo and four tenth\% of cases without $\mathrm{LN}$ metastasis (N0) showed low expression, while $57.1 \%$ of cases with $\mathrm{N} 1$ and $78.9 \%$ of cases with N2 showed high expression. These results were in agreement with studies performed by Yang et al., (16) in CRC, Li et al., (27) in gastric carcinoma and Althobiti et al., (30) in invasive breast carcinoma. Beside the role of ALDH1A1 in promoting EMT which contributes to invasive and metastatic tumor growth, ALDH1A1 was found to stimulate tumor invasion and $\mathrm{LN}$ metastasis via the $\mathrm{Wnt} / \beta$ catenin signaling pathway. This pathway was found to be associated with retinoic acid signaling pathway $(37,16)$.

On the contrary, van der Waals et al., (15) found insignificant statistical association between ALDH1A1 expression and LN metastasis in CRC. This may be due to different interpretation of ALDH1A1 expression and different number of cases with positive and negative lymph node metastasis.

There was statistically insignificant difference between ALDH1A1 expression and distant metastasis in studied cases. Fifty-five and eight tenths percent of cases without distant metastasis (M0) showed high expression, while $71.4 \%$ of cases with distant metastasis (M1) showed low expression. These results were in agreement with studies performed by Yang et al., (16) in CRC and Ye et al., (38) in gastric neuroendocrine carcinoma. ALDH1A1 was found to be associated with activation of angiogenic factors, such as hypoxia inducible factor- $1 \alpha$ (HIF-1 $\alpha)$ and proangiogenic factors, such as vascular endothelial growth factor (VEGF). This 
suggests that ALDH1A1 may promote tumor metastasis (39). However, $71.4 \%$ of cases with distant metastasis showed low expression which may be due to limited number of cases with distant metastasis.

In our study, there was a highly significant statistical difference between ALDH1A1 expression in studied cases and TNM stage . Eighty six and seven tenths percent of cases with stage II and 71.4 of cases with stage IV showed low expression, while $78.6 \%$ of cases with stage III showed high expression. Many studies showed that ALDH1A1 expression was significantly associated with advanced tumor stage indicating the role of ALDH1A1 in tumor progression and advanced stage. These studies were carried out by Li et al., (40) on lung adenocarcinoma, Li et al., (27) on gastric carcinoma and Xing et al., (41) in papillary thyroid carcinoma. On the contrary, other studies showed no significant relation between ALDH1A1 expression and TNM stage including Yang et al., (16) on CRC, Liu et al., (34) on gastric carcinoma and Khalifa et al., (42) on epithelial ovarian tumors. These opposing results in CRC may have resulted from the differing populations and diets across the studies, as well as any differences in ALDH1A1 gene mutations. The differences in ALDH1A1 expression between studies could arise from variations in the tissue specificity, stage distribution, use of different clones of antibodies and different means of interpretation.

In conclusion, high ALDH1A1 expression was associated with right sided tumors, lymphovascular invasion, perineural invasion and lymph node metastasis in CRC. ALDH1A1 may play an important role in tumor invasion and lymph node metastasis and may work as a useful marker for prognosis of CRC. Further studies on ALDH1A1expression on a larger number of cases are recommended to clarify its association with advanced tumor stage. Further studies using different molecular methods on ALDH1A1 are recommended to detect the mechanisms by which ALDH1A1 may contribute to the development and progression of CRC.

\section{References:}

1. Bray F, Ferlay J, Soerjomataram I, Siegel RL, Torre LA, Jemal A. Global cancer statistics 2018: GLOBOCAN estimates of incidence and mortality worldwide for 36 cancers in 185 countries. CA: a cancer journal for clinicians. 2018 Nov;68(6):394424.

2. Mokhtar N, Salama A, Badawy O, Khorshed E, Mohamed G, Ibrahim M, et al. Cancer pathology registry 2000-2011. Cairo, Egypt: 
National Cancer Institute Cairo University. Back to cited text. 2016(18).

3. Mahfouz EM, Sadek RR, Abdel-Latief WM, Mosallem FA, Hassan EE. The role of dietary and lifestyle factors in the development of colorectal cancer: case control study in Minia, Egypt. Cent Eur J Public Health. 2014 Dec 1;22(4):215-2.

4. Kulendran M, Stebbing JF, Marks CG, Rockall TA. Predictive and prognostic factors in colorectal cancer: a personalized approach. Cancers. 2011 Jun;3(2):1622-38.

5. Wu Z, Huang X, Han X, Li Z, Zhu Q, Yan J, Yu S, Jin Z, Wang Z, Zheng Q, Wang Y. The chemokine CXCL9 expression is associated with better prognosis for colorectal carcinoma patients. Biomedicine \& Pharmacotherapy. 2016 Mar 1;78:8-13.

6. Wahab SR, Islam F, Gopalan V, Lam AK. The identifications and clinical implications of cancer stem cells in colorectal cancer. Clinical Colorectal Cancer. 2017 Jun 1;16(2):93-102.

7. Vassalli G. Aldehyde Dehydrogenases: Not Just Markers, but Functional Regulators of Stem Cells. Stem cells international. 2019 Jan 13; 2019:3904645.

8. Markowitz SD, Bertagnolli MM. Molecular basis of colorectal cancer. New England Journal of Medicine. 2009 Dec 17;361(25):2449-60.

9. Tomita H, Tanaka K, Tanaka T, Hara A. Aldehyde dehydrogenase 1A1 in stem cells and cancer. Oncotarget. 2016 Mar 8;7(10):11018.
10. Awan R, Sirinukunwattana K, Epstein D, Jefferyes S, Qidwai U, Aftab Z, Mujeeb I, Snead D, Rajpoot N. Glandular morphometrics for objective grading of colorectal adenocarcinoma histology images. Scientific reports. 2017 Dec 4;7(1):1-2.

11. Amin MB, Greene FL, Edge SB, Compton CC, Gershenwald JE, Brookland RK, Meyer L, Gress DM, Byrd DR, Winchester DP. The eighth edition AJCC cancer staging manual: continuing to build a bridge from a population-based to a more "personalized" approach to cancer staging. CA: a cancer journal for clinicians. 2017 Mar;67(2):93-9.

12. Nagtegaal ID, Arends MJ, Odze RD. Tumors of colon and rectum. In: WHO classification of tumors, 5th edition, Digestive system tumors, edited by WHO Classification of Tumors Editorial Board. International Agency for Research on Cancer, pp 157-188, 2019.

13. Kalantari E, Saadi FH, Asgari M, Shariftabrizi A, Roudi R, Madjd Z. Increased expression of ALDH1A1 in prostate cancer is correlated with tumor aggressiveness: a tissue microarray study of Iranian patients. Applied immunohistochemistry \& molecular morphology. 2017 Sep 1;25(8):592-8.

14. Wang K, Chen X, Zhan Y, Jiang W, Liu X, Wang $\mathrm{X}, \mathrm{Wu} \mathrm{B}$. Increased expression of ALDH1A1 protein is associated with poor prognosis in clear cell renal cell carcinoma. Medical oncology. 2013 Jun 1;30(2):574. 
15. van der Waals LM, Borel Rinkes IH, Kranenburg O. ALDH1A1 expression is associated with poor differentiation,'rightsidedness' and poor survival in human colorectal cancer. PloS one. 2018 Oct 11;13(10):e0205536.

16. Yang W, Wang Y, Wang W, Chen Z, Bai G. Expression of aldehyde dehydrogenase 1A1 (ALDH1A1) as a prognostic biomarker in colorectal cancer using immunohistochemistry. Medical science monitor: international medical journal of experimental and clinical research. 2018; $24: 2864$

17. Xu SL, Zeng DZ, Dong WG, Ding YQ, Rao J, Duan JJ, Liu Q, Yang J, Zhan N, Liu Y, $\mathrm{Hu}$ QP. Distinct patterns of ALDH1A1 expression predict metastasis and poor outcome of colorectal carcinoma. International journal of clinical and experimental pathology. 2014;7(6):2976.

18. Thota R, Fang $\mathrm{X}$, Subbiah $\mathrm{S}$. Clinicopathological features and survival outcomes of primary signet ring cell and mucinous adenocarcinoma of colon: retrospective analysis of VACCR database. Journal of gastrointestinal oncology. 2014 Feb;5(1):18.

19. Nitsche U, Zimmermann A, Späth C, Müller T, Maak M, Schuster T, Slotta-Huspenina J, Käser SA, Michalski CW, Janssen KP, Friess H. Mucinous and signet-ring cell colorectal cancers differ from classical adenocarcinomas in tumor biology and prognosis. Annals of surgery. 2013 Nov;258(5):775.
20. Wu S, WU SJ, HE YL, Cai SR, Zhang CH, Zhang XH, et al. Clinicopathologic features and survival of patients with colorectal mucinous, signet-ring cell or non-mucinous adenocarcinoma: experience at an institution in southern China. Chinese medical journal. 2009 Jul 1;122(13):1486-91.

21. Chew MH, Yeo SA, Ng ZP, Lim KH, Koh $\mathrm{PK}, \mathrm{Ng} \mathrm{KH}$, et al. Critical analysis of mucin and signet ring cell as prognostic factors in an Asian population of 2,764 sporadic colorectal cancers. International journal of colorectal disease. 2010 Oct 1;25(10):12219.

22. Hyngstrom JR, Hu CY, Xing Y, You YN, Feig BW, Skibber JM, et al. Clinicopathology and outcomes for mucinous and signet ring colorectal adenocarcinoma: analysis from the National Cancer Data Base. Annals of surgical oncology. 2012 Sep 1;19(9):2814-21.

23. Goldblum JR, Lamps LW, McKenney JK, Myers JL. Rosai and Ackerman's Surgical Pathology E-Book. Elsevier Health Sciences; eleventh edition, pp 676-684, 2017 Oct 25 .

24. Derwinger K, Kodeda K, Bexe-Lindskog E, Taflin H. Tumour differentiation grade is associated with TNM staging and the risk of node metastasis in colorectal cancer. Acta oncologica. 2010 Jan 1;49(1):57-62.

25. Holah NS, Aiad HA, Asaad NY, Elkhouly EA, Lasheen AG. Evaluation of the role of ALDH1 as cancer stem cell marker in colorectal carcinoma: an immunohistochemical study. Journal of 
Clinical and Diagnostic Research: Jcdr. 2017 Jan;11(1):EC17.

26. Stintzing S, Tejpar S, Gibbs P, Thiebach L, Lenz HJ. Understanding the role of primary tumour localisation in colorectal cancer treatment and outcomes. European Journal of Cancer. 2017 Oct 1;84:69-80.

27. Li XS, Xu Q, Fu XY, Luo WS. ALDH1A1 overexpression is associated with the progression and prognosis in gastric cancer. BMC cancer. 2014 Dec 1;14(1):705.

28. Wang B, Chen X, Wang Z, Xiong W, Xu T, Zhao X, Cao Y, Guo Y, Li L, Chen S, Huang S. Aldehyde dehydrogenase 1A1 increases NADH levels and promotes tumor growth via glutathione/dihydrolipoic aciddependent NAD+ reduction. Oncotarget. 2017 Sep 15;8(40):67043.

29. Lugli A, Iezzi G, Hostettler I, Muraro MG, Mele V, Tornillo L, Carafa V, Spagnoli G, Terracciano L, Zlobec I. Prognostic impact of the expression of putative cancer stem cell markers CD133, CD166, CD44s, EpCAM, and ALDH1 in colorectal cancer. British journal of cancer. 2010 Jul;103(3):382-90.

30. Althobiti M, El Ansari R, Aleskandarany M, Joseph C, Toss MS, Green AR, Rakha EA. The prognostic significance of ALDH1A1 expression in early invasive breast cancer. Histopathology 77, 437-447. 2020 May 5.

31. Penumatsa K, Edassery SL, Barua A, Bradaric MJ, Luborsky JL. Differential expression of aldehyde dehydrogenase 1a1 (ALDH1) in normal ovary and serous ovarian tumors. Journal of ovarian research. 2010 Dec 1;3(1):28.

32. Kahlert C, Bergmann F, Beck J, Welsch T, Mogler C, Herpel E, Dutta S, Niemietz T, Koch M, Weitz J. Low expression of aldehyde deyhdrogenase 1A1 (ALDH1A1) is a prognostic marker for poor survival in pancreatic cancer. BMC cancer. 2011 Dec;11(1):1-0.

33. Tanaka K, Tomita $\mathrm{H}$, Hisamatsu $\mathrm{K}$, Nakashima T, Hatano Y, Sasaki Y, Osada S, Tanaka T, Miyazaki T, Yoshida K, Hara A. ALDH1A1-overexpressing cells are differentiated cells but not cancer stem or progenitor cells in human hepatocellular carcinoma. Oncotarget. 2015 Sep 22;6(28):24722.

34. Liu WT, Liu WB, Gao M, Zhang YY, Gu KS. Expression of ALDH1A1 and CD133 is associated with the prognosis and effect of different chemotherapeutic regimens in gastric cancer. Oncology Letters. 2019 Nov $1 ; 18(5): 4573-82$.

35. Biddle A, Liang X, Gammon L, Fazil B, Harper LJ, Emich H, Costea DE, Mackenzie IC. Cancer stem cells in squamous cell carcinoma switch between two distinct phenotypes that are preferentially migratory or proliferative. Cancer research. 2011 Aug 1;71(15):5317-26.

36. Masoud SG, Bakr M, Emara N, Nasif S. The Significance of Aldehyde Dehydrogenase 1A1 Expression in Benign Prostatic Hyperplasia, Prostatic Intraepithelial Neoplasia and Prostatic Adenocarcinoma. Benha Medical Journal. 2020 May 1;37(1):207-19. 
37. Debeb BG, Lacerda L, Xu W, Larson R, Solley T, Atkinson R, Sulman EP, Ueno NT, Krishnamurthy S, Reuben JM, Buchholz TA. Histone deacetylase inhibitors stimulate dedifferentiation of human breast cancer cells through $\mathrm{WNT} / \beta$-catenin signaling. Stem cells. 2012 Nov;30(11):2366-77.

38. Ye Y, Zhang S, Chen Y, Wang X, Wang P. High ALDH1A1 expression indicates a poor prognosis in gastric neuroendocrine carcinoma. Pathology-Research and Practice. 2018 Feb 1;214(2):268-72.

39. Ciccone V, Terzuoli E, Donnini S, Giachetti A, Morbidelli L, Ziche M. Stemness marker ALDH1A1 promotes tumor angiogenesis via retinoic acid/HIF-1 $\alpha / \mathrm{VEGF}$ signalling in MCF-7 breast cancer cells. Journal of
Experimental \& Clinical Cancer Research. 2018 Dec 1;37(1):311.

40. Li X, Wan L, Geng J, Wu CL, Bai X. Aldehyde dehydrogenase 1A1 possesses stem-like properties and predicts lung cancer patient outcome. Journal of Thoracic Oncology. 2012 Aug 1;7(8):1235-45.

41. Xing Y, Luo DY, Long MY, Zeng SL, Li HH. High ALDH1A1 expression correlates with poor survival in papillary thyroid carcinoma. World journal of surgical oncology. 2014 Dec 1;12(1):29.

42. Khalifa S, Muhammad ME, Khairy MD, Rasha A, Hosni HN, Abd E, Ahmed M. Aldehyde dehydrogenase 1A1 expression in ovarian epithelial tumors. Journal of Obstetrics, Gynecology and Cancer Research (JOGCR). 2018 Mar 10;3(1):13-8.

To cite this article: Eman M. Zedan, Hanaa M. Ali, Nashwa M. Emara, Hala A. Agina. The Significance of Aldehyde Dehydrogenase 1A1 Expression in Colorectal Carcinoma. BMFJ 2022;39 (academic issue):1-18. 